\title{
Concrete as Heritage: The Social Perception from Heritage Criteria Perspective. The Eduardo Torroja's Work
}

\author{
Gema Ramírez-Guerrero*, Javier García-Onetti, Juan Adolfo Chica-Ruiz, Manuel Arcila-Garrido \\ Department of History, Geography and Philosophy, University of Cadiz, Cádiz 11002, Spain
}

Corresponding Author Email: gema.ramirez@uca.es

https://doi.org/10.18280/ijdne.150603

Received: 8 February 2020

Accepted: 30 October 2020

\section{Keywords:}

concrete-based heritage, cultural tourism, Eduardo Torroja, Eduardo Torroja Institute, tourist potential, Zarzuela hippodrome

\begin{abstract}
Eduardo Torroja Miret (1899-1961) was one of the most important Spanish engineers. His understanding of structures and materials made him a world reference in the field of engineering and architecture. Due to the lack of ornamentation in his works and the lack of heritage interpretation aimed at a non-specialist public, many of his works sometimes go unnoticed by inexperienced eyes and, despite his important legacy, Torroja remains a great unknown. This paper reports on the existing heritage perception of two of his most outstanding works in Spain, the Zarzuela Hippodrome and the Instituto Técnico de la Construcción y el Cemento (Eduardo Torroja Institute). To this end, surveys and interviews were carried out with visitors to both buildings based on different heritage criteria, such as their architectural importance, aesthetics, significance or representativeness, but also from the point of view of the available tourist infrastructure. The results show a lack of appreciation in the heritage criteria related to its architectural, historical and aesthetic values, combined with a lack of knowledge about Torroja and its way of understanding architectural beauty.
\end{abstract}

\section{INTRODUCTION}

Due to its malleability, hardness and endless possibilities, in terms of texture and colour, concrete became the building material par excellence to design most of the buildings around the world, some of them with a great architectural, historical and cultural relevance [1].

It is difficult to talk about concrete as heritage without mentioning Eduardo Torroja as one of the main precursors of the development of reinforced and prestressed concrete in the $20^{\text {th }}$-century [2]. The relationship between structure, technique and aesthetics is part of Torroja's work, as he describes it: for the first time in the history of art, the structure has acquired an independent personality, so that its own aesthetic quality can be appreciated [3]. He stands out, on the one side, for the refined technique used and the architectural clarity of his sets and, on the other side, for the prominence he gives to concrete as the protagonist in his works, with no other ornamentation than the structure itself. These characteristics can be seen in two of his most representative works in Spain: The Zarzuela Hippodrome [4] and the Instituto Técnico de la Construction y el Cemento Eduardo Torroja (henceforth ETI) [5].

In some countries, certain concrete-based modernist assets are considered as cultural heritage and properly protected, such as Dessau Bauhaus by Walter Gropius in Germany, listed as a UNESCO World Heritage Site in 1996. However, the social appreciation regarding this type of assets seems to be weakened [6]. Concrete is usually considered as an ignoble material, used mainly for the construction of civil buildings in urban environments (e.g. bridges, institutes, railway stations or hospitals), its value as an artistic element is not recognized by the general non-specialist population [7]. This fact limits the enhancement of this typology of cultural assets, which makes them the great forgotten ones in many tourist destinations.

Tourism, conceived as a tool for social awareness and conservation of cultural assets [8] is an opportunity to bring Eduardo Torroja's legacy closer to the general population. At the same time, it works as a thread to eternalize the memory of a historical period and a political context in turmoil.

The lack of tourism and cultural studies and reflections about this kind of heritage, creates a documentary gap about its real value. It is through knowledge about its historical context and its ethic and aesthetical aspects that tools for its protection and conservation can be generated, allowing us to understand its architectural contemporaneity and how to aware to society. The concrete-based cultural assets enhancement becomes, therefore, in a pending subject.

This paper takes steps to fill this gap, firstly through a brief analysis of the particularities of concrete-based cultural heritage and the problems arising from lack of conservation, and secondly through an analysis of the heritage perception received by visitors to both buildings.

This paper commences with a brief analysis of the theories developed in research into tourism as a heritage ally. Subsequently, the possibilities of the concrete-based cultural heritage as tourist attractions are briefly analyzed, starting previously with an analysis of them particularities as architectural elements. This is followed by the methodology used in this study. Finally, the findings are presented, followed by a discussion about the implications for the Zarzuela Hippodrome and the ETI, the elements that strengthen and weaken the tourist experience, and the utility, merits and effectiveness of the method used. The paper concludes with a series of recommendations for the enhancement of both buildings, from a sustainable, social and respectful perspective. 


\section{THE PARTNETSHIP BETWEEN TOURISM AND CULTURAL HERITAGE}

Tourism has become one of the most common tools to "make profitable" and, therefore, "industrialize" certain monuments $[9,10]$. Although both terms: "to make profitable" and "to industrialize" could reflect negative aspects if they are related to heritage [11]. We need only look at Florence or Venice, both of which are overcrowded with tourists, or at Kyoto, whose city is deteriorating by the day to see what the overcrowding resulting from inappropriate tourist management can bring about in cities with a significant heritage burden. As mentioned by Choay, the cult of historical heritage today requires much more than the confirmation of a satisfaction [8]. However, a correct and respectful tourism management of cultural heritage can represent the adaptation of certain cultural resources, in danger of disappearing, into products suitable for heritage tourism, whose purpose is not only the satisfaction of the visitor, but also its conservation, enhancement and appreciation as a legacy of our history [12].

In Europe, as elsewhere, heritage is also denounced for reasons other than tourism such as the impossibility of giving new uses to historical buildings, urban development exploitation, high maintenance costs and low or no profitability or paralyzing effect on urban projects, etc. [13].

Each of these cases tends to occur to a greater extent in certain buildings built during the $20^{\text {th }}$-century with concrete as the main differentiating element. Buildings such as the Imperial Hotel in Tokyo, a masterpiece by Frank Lloyd Wright (1915), demolished in 1968; or Erich Mendelson's Schoken department store (1924) in Sttugart, demolished in 1955, among many others. Despite the numerous mobilizations that some demolitions have caused, many of these protests, although coming from prestigious voices, were those of a minority confronted with general indifference [8]. Therefore, sometimes these buildings, both for public administrations and for society in general, are not part of the list of buildings to preserve, being considered buildings, aesthetically, in bad taste and/or with trivial functions not worthy of preservation.

\section{AIM AND OBJETIVES}

In order to know to what extent a building is recognized as a valuable cultural asset to be preserved, loved and therefore, visited, it is necessary to know where the existing social appreciation lies [14]. Consequently, the general objective of the present study is to know the social perception around the Zarzuela Hippodrome and the ETI, which is an opportunity to be able to improve the decision-making or to propose measures, in future works that allow to enhance its value and to reach a greater public.

Likewise, it is considered fundamental to involve the community in projects or studies related to the monument to be evaluated. This is described by Washington Charter for the Conservation of Historic Cities and Urban Areas in 1987, which establishes that the participation and the involvement of the residents are essential for the success of the conservation program [sic] and should be encouraged. The conservation of historic towns and urban areas concerns their residents first of all [15].

Therefore, considering the context where this study is located, the specific objectives are:

(1) To determine the appreciation perceived by users who are familiar with the buildings and their attributes as cultural assets, in order to facilitate decision-making in the development of initiatives to promote their architectural and cultural value.

(2) To understand the (perceptive) potential of both buildings to improve their value and awareness about their cultural and architectural importance.

\section{RESEARCH METHOD}

We have been inspired by the method applied in previous studies [16] for the analysis of the heritage perception of modernist buildings.

(1) The starting point involved several researchers conducting the valuation of concrete-based heritage. It was necessary a bibliographic search of the published studies related to the architectural background of concrete-based cultural assets and monographs and papers about heritage perception, the partnership between tourism and heritage and cultural tourism.

(2) Non-parametric techniques were incorporated based on the implementation of surveys and interviews to obtain the required data from visitors who attend the Zarzuela hippodrome and the Eduardo Torroja Institute.

\subsection{Questionnaire design}

Both questionnaires were designed considering three different sections: The first section, "user profile", contains general questions characterizing users' gender, educational level, provenance, level of knowledge and type of event attended. For the second and third sections, we were inspired by the heritage criteria for the outstanding universal value of the assets by the World Heritage Convention (1972). Several heritage criteria were chosen for the assessment of both buildings. The second section contains questions related to the satisfaction in multiple points of the buildings and the third section contains questions about the cultural uses.

For the selection of the questions, the nature of the content and its function was considered, including the next kind of questions:

(1) Closed (pre-coded or fixed response).

(2) Multiple choice:

- Answer Range: Multiple choice of answers.

- Open answer: leaving the possibility of adding options not contemplated in the given alternatives.

- Estimation questions: A Likert scale (1-5), with one being the worst scenario and five the best.

(3) Consistency and control questions, to check the consistency of the respondent's answers.

The whole pattern questionnaire contains 20 questions. The structure, quality and clearness of the questionnaire was tested previously in the University of Cádiz (Spain) as historical building in February 2018.

\subsection{Data collection}

We applied the stratified random sampling. Both questionnaires were distributed through on-site interviews and with invitation cards where the users could access to the online form through a QR code. Both the administration of the hippodrome and the ETI were actively involved in the distribution of the online forms. In the first case to the visitors 
and members of the hippodrome club and in the second case to the employees and companies that organize visits to the institute.

In the case of the Zarzuela hippodrome, the data collection was conducted in three periods throughout the year 2018-2019 to achieve a transverse time dimension: July-September, October-November and December-March.

The poll was conducted in two phases:

(1) Firstly, the target population was stratified by events: the first stratum was in winter, where the races are held in the morning; and the second stratum was during the summer, held in the evening.

(2) Secondly, an investigator in different points around the hippodrome conducted the questionnaires: stands and shopping/gastronomy area.

To calculate the sample needed, the population (visitors) based on data obtained in $2018(\mathrm{~N}=124,000)$ was considered. Finally, $371(n=371)$ responses were chosen for this study.

In the case of ETI, given the current activity and functions of the institute, the implementation of on-site surveys was not possible. It currently belongs to the Consejo Superior de Investigaciones Científicas (CSIC), being the Instituto de Ciencias de la Construcción Eduardo Torroja. This fact has limited the data collection since public access is not allowed. Therefore, the questionnaire was applied to the building's own staff, in addition to a series of interviews with external visitors who accessed the building through a previously arranged guided tour. A total of $65(n=65)$ responses were collected from 173 workers $(\mathrm{N}=173)$ who are listed in the current directory of the institute [5]. In addition, seven interviews were conducted with external visitors. The data were collected in the period between October and November 2018.

This work is not part of a probabilistic study. The results presented are an approximation, pending a greater exhaustiveness in future studies. Likewise, due to the conditioning factors of the activity that the ETI is currently developing, it has not been possible to obtain a representative sample of the population not specialized in architecture and/or engineering, so the results could be distorted due to the training of the users interviewed in the field of study of Eduardo Torroja himself.

However, the results demonstrate a useful approach, unknown in other studies, to the existing perception of Torroja's work from a perspective that goes beyond its value as architectural elements.

\section{RESULTS}

From the data collected in the fieldwork carried out in both buildings, we obtain useful information that allows us to first define the profile of the respondent in both cases, analysing issues such as gender, age or origin.

Secondly, the visitor's satisfaction with the buildings as a whole (thematic block 2) and, finally, the cultural uses of the buildings (thematic block 3 ).

\subsection{The users' profile}

The general description of the visitor is in Table 1. The age range, gender and level of knowledge of both buildings are considered, e.g. knowledge related to the Zarzuela hippodrome as a Cultural Asset and its link with Eduardo Torroja.

In the case of the Zarzuela hippodrome, Table 1 shows that, the $63 \%$ of the respondents were men. The most frequent characteristics are visitors from 25 to 44 years old followed by visitors from 45 to 64 years old, with limited knowledge about the building as $A C I$ and about Eduardo Torroja as the engineer who participated in its construction.

According to the provenance, the responses collected reflect that $97 \%$ have Spanish nationality of which, $93 \%$ are from Madrid.

In addition to the data provided in Table 1 , the results collected by the questionnaires show that in terms of educational level, $76 \%$ of the respondents have higher education, followed by $18 \%$ who affirm to have secondary education. An important fact from results reports that $72 \%$ of respondents visit the hippodrome on several occasions. It should be noted that $90 \%$ of respondents know the hippodrome by family and friends, which could place the hippodrome as a usual leisure place.

In the case of the ETI and based on the respondents' profile, the $55.4 \%$ of the respondents are female. Regarding the provenance, the responses collected reflect that $65 \%$ of the respondents are from Madrid. For both women and men, the main study field of the users interviewed is engineering sciences and architecture $(60 \%)$.

Regarding the interviews conducted with users outside the institute, of the total number of interviews, four were conducted with women and three with men, with ages ranging from 25 to 44,45 to 64 and over 65 . The provenance of the seven users interviewed is Madrid.

Table 1. General description of the users participated in the surveys $(n=436)$

\begin{tabular}{|c|c|c|c|c|c|c|c|}
\hline \multirow[b]{3}{*}{ Data split by: } & & \multirow[b]{3}{*}{ Freq. } & \multirow[b]{3}{*}{$(\%)$} & \multicolumn{4}{|c|}{ Building } \\
\hline & & & & \multicolumn{2}{|c|}{ ETI } & \multicolumn{2}{|c|}{ Zarzuela hippodrome } \\
\hline & & & & Freq. & $(\%)$ & Freq. & $(\%)$ \\
\hline \multirow[t]{4}{*}{ Age range } & $18 \_24$ & 63 & $14 \%$ & 7 & $10 \%$ & 56 & $15 \%$ \\
\hline & $25 \_44$ & 216 & $49 \%$ & 42 & $64 \%$ & 174 & $47 \%$ \\
\hline & $45 \_64$ & 125 & $28 \%$ & 16 & $24 \%$ & 109 & $29 \%$ \\
\hline & $>65$ & 32 & $7 \%$ & 0 & $0 \%$ & 32 & $9 \%$ \\
\hline \multirow[t]{2}{*}{ Gender } & Female & 173 & $39 \%$ & 36 & $55 \%$ & 137 & $37 \%$ \\
\hline & Male & 263 & $60 \%$ & 29 & $44 \%$ & 234 & $63 \%$ \\
\hline \multirow{2}{*}{ Knowledge: Building as ACI* } & Yes & 26 & $6 \%$ & 0 & $0 \%$ & 26 & $7 \%$ \\
\hline & Not & 345 & $79 \%$ & 0 & $0 \%$ & 345 & $93 \%$ \\
\hline \multirow{2}{*}{ Knowledge: Eduardo Torroja } & Yes & 91 & $20 \%$ & 65 & $100 \%$ & 26 & $7 \%$ \\
\hline & Not & 345 & $79 \%$ & 0 & $0 \%$ & 345 & $93 \%$ \\
\hline
\end{tabular}




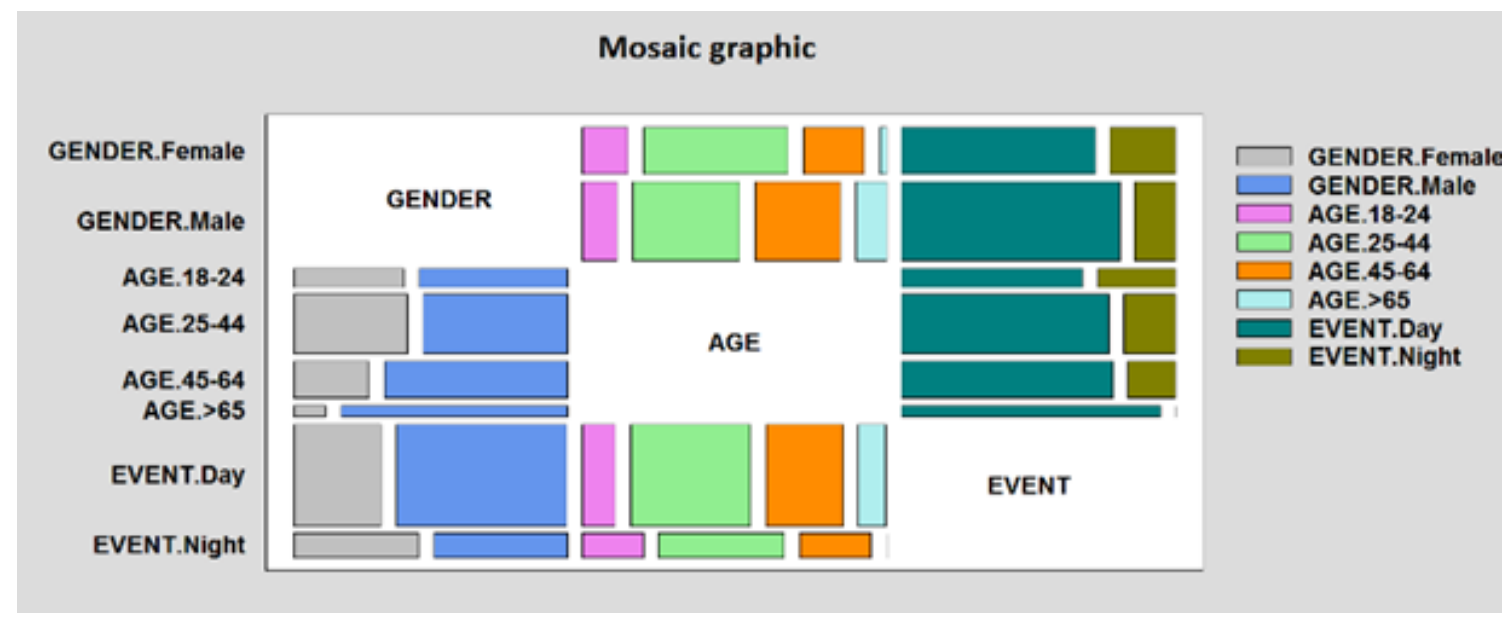

Figure 1. Mosaic graphic. Event, Age and Gender. Zarzuela racecourse [16]

The races at the hippodrome are held in daytime and nighttime events, depending on the time of year. Consequently, in order to differentiate the profiles that may occur in different periods, the Gender and Age variables are analyzed below, considering the Event variable (Table 2 and Figure 1).

Table 2. Table Burt - Inertia calculated: Event, Age and Gender. Zarzuela hippodrome [16]

\begin{tabular}{|c|c|c|c|c|c|c|}
\hline & Female & Male & 18-24 & $25-44$ & $45-64$ & $>65$ \\
\hline & 100 & 199 & 39 & 139 & 89 & 32 \\
\hline Event.Night & 37 & 35 & 17 & 35 & 20 & 0 \\
\hline
\end{tabular}

The table Burt shows the simultaneous occurrence of pairs of categories for three variables: Event, Age and Gender.

The symmetric table shows the frequencies for all variables combinations (Event, Age and Gender) related to the main profile of the hippodrome's users.

Regarding the differentiated profile by events, the results report that both in the daytime event and in the nighttime event, the age range is 25 to 44 years old, with the predominant gender being male in daytime events $(67 \%)$ and both genders, male and female, being equal in nighttime events $(51 \%$ and $49 \%$ respectively).

In terms of the respondents' main motivations, the data shows that $56 \%$ go to the hippodrome for horseracing, followed by the leisure and social environment (24\%). As for the Eduardo Torroja Museum and the Miguel Ángel Ribera Library, the results show that $98 \%$ of the respondents did not know that both locations existed. Therefore, among those who did know it existed, only $1 \%$ visited the museum and none the library.

\subsection{Thematic block 2. Set of buildings: Satisfaction in multiple points and information related to the group of buildings}

To introduce this thematic block, some questions were included to evaluate the general knowledge about the building.

Eduardo Torroja Institute: Did you know who designed and built the building before you visited? The results reflect that $100 \%$ of the respondents (institute's staff) knew their author's name and only $45 \%$ of the external respondents knew it.

Zarzuela hippodrome: Did you know that $\mathrm{ZH}$ is protected as a cultural asset (ACI) since 2009? And Did you know who was the engineer who participated in the construction of the ZH?
The result is the same in both questions, $93 \%$ of the respondents did not know the answer. This point can be quite enlightening to understand how important the knowledge is for the proper valuation of heritage.

It should be mentioned that it is understandable that the percentage increases in the case of the institute, because the building represents the life and work of the author himself. The elements evaluated have been those related to heritage criteria, such as historical, architectural, aesthetic and cultural perspective. Likewise, external elements such as access, signage and seating in the stands are evaluated.

In the case of the ETI, due to the differentiation between the expert group and the external respondents, the results are shown as follows (see Figure 2), being 1 the worst scenario and 5 the best:

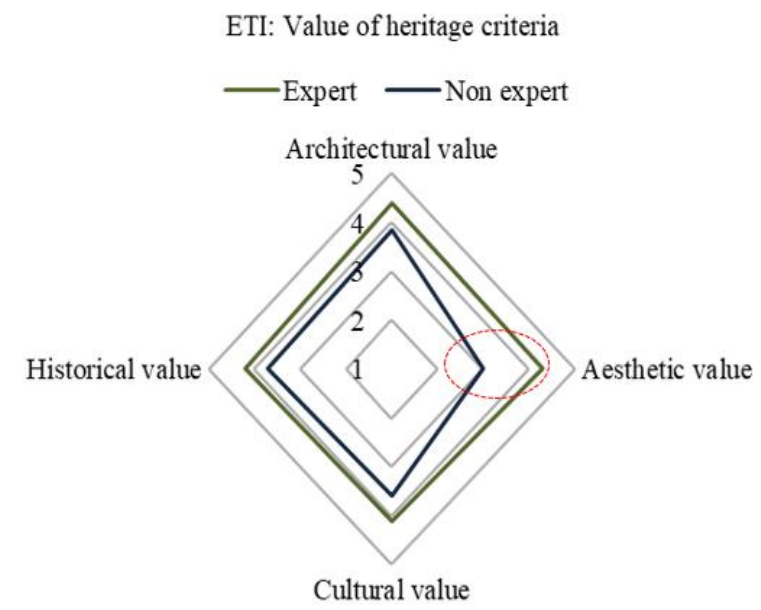

Figure 2. Surface chart. ETI: Value of heritage criteria. Eduardo Torroja Institute

In order to know the exact measurements of each valuation, the Table 3 shows the results obtained with their corresponding weights (0-1).

As can be noted in the table and figure above, in the case of the experts, the highest ratings are achieved in points 4 and 5, with aspects related to architectural and historical value, followed by cultural and aesthetic value.

In the case of external respondents (non-experts), the ratings are reduced to 3 and 4 , with cultural value being the best evaluated, followed by architectural, historical and aesthetic value. 
Table 3. Weights of the ratings assigned to the Eduardo Torroja Institute

\begin{tabular}{ccccc}
\hline & \multicolumn{4}{c}{ EXPERTS } \\
\cline { 2 - 5 } Rating scale & Architectural v. & Aesthetic v. & Cultural v. & Historical v. \\
\hline 5 & 0.5076 & 0.446 & 0.3384 & 0.4153 \\
4 & 0.4153 & 0.461 & 0.4769 & 0.4153 \\
3 & 0.0615 & 0.061 & 0.1538 & 0.1384 \\
2 & 0.0000 & 0.015 & 0.0153 & 0.0153 \\
1 & 0.0153 & 0.015 & 0.0153 & 0.0153 \\
& & NON-EXPERTS & \\
\cline { 2 - 5 } Rating scale & Architectural v. & Aesthetic v. & Cultural v. & Historical v. \\
\hline 5 & 0.1428 & 0.0000 & 0.0000 & 0.1428 \\
4 & 0.5714 & 0.2857 & 0.7142 & 0.4285 \\
3 & 0.2857 & 0.4285 & 0.1428 & 0.4285 \\
2 & 0.0000 & 0.2857 & 0.1428 & 0 \\
1 & 0 & 0 & 0 & 0 \\
\hline
\end{tabular}

Table 4. Weights of the ratings assigned to the Zarzuela hippodrome

\begin{tabular}{ccccc}
\hline Rating scale & Architectural v. & Aesthetic v. & Cultural v. & Historical v. \\
\hline 5 & 0.5538 & 0.5538 & 0.3543 & 0.4671 \\
4 & 0.3175 & 0.3359 & 0.3464 & 0.3858 \\
3 & 0.0866 & 0.0866 & 0.1758 & 0.0866 \\
2 & 0.0262 & 0.0105 & 0.0498 & 0.0288 \\
1 & 0 & 0 & 0.0131 & 0 \\
\hline
\end{tabular}

The reasons of the difference in both groups (experts and non-experts), could be due to the lack of information in the building's environment. Currently, there are no signs near the building that facilitate its heritage interpretation. On the other side, since access to the public is not allowed, it is more difficult for the non-specialized public to grasp the value of the building in the same way as the institute's own workers do.

Therefore, the lack of information about the buildings seems to be a determining factor for their correct valuation. On the other side, in terms of signage, maintenance, access and the beauty of the surroundings, the data reflect considerable differences between expert and non-expert respondents (see Figure 3):

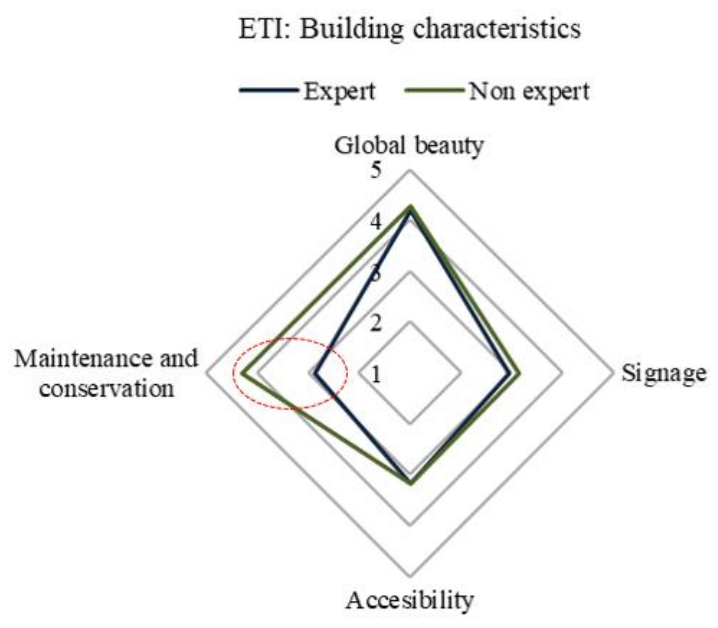

Figure 3. Surface chart. Building characteristics. Eduardo Torroja Institute

It should be noted that the elements evaluated in relation to the maintenance and conservation of the building show significant differences, with the group of experts having the most negative opinion (2.8) as opposed to the group of nonexperts (4.2). In view of the results, the assessments given by the group of experts are a determining reflection of the actions that should be carried out in the building for its correct maintenance and conservation.

In the case of the Zarzuela Hippodrome, the following Table 4 shows the ratings given by respondents $(0-1)$.

The data collected report the high valuation given in the architectural and aesthetic value of the building, followed by the historical value. On the other side, regarding the available tourist information, $26 \%$ think that it is not enough (2), followed by $24 \%$ who say that it is insufficient. They add that the information provided through the web, in relation to tourist activities is deficient and that there is no information in the city of Madrid nor in the nearby provinces. They also add that the dissemination and publicity promoted by the hippodrome about its activities, beyond horseracing, is very low.

\subsection{Thematic block 3. Cultural uses: Different uses of the buildings}

In the third and last block of the questionnaire, information was obtained about the variables related to the cultural uses of the buildings (guided tours, cultural events, exhibitions or information seminars). In the case of the ETI, the evaluations were made on the elements related to the use of the building and its compatibility with tourist and education activities, considering the current function of the institute as a scientific research center (Figure 4).

The institute's current activities are mainly focused on research activities, followed by occasional cultural events. As Figure 4 shows, tourism activities (visits to the institute) are not usually carried out normally, so their compatibility with such activity is rated at 2.6 for experts and 3 for external respondents. Finally, two more questions were included about the tourist compatibility of the building.

First, in response to the question Do you think that certain activities related to cultural tourism could be compatible with the current activity of the building? $48 \%$ of the expert respondents answered that perhaps certain tourism activities could be developed that are compatible with the function of the building, followed by $43 \%$ who answered No. In the case of external respondents, 3 respondents answered Yes, 3 answered Perhaps and 1 said No. 
ETI: Cultural uses of the building

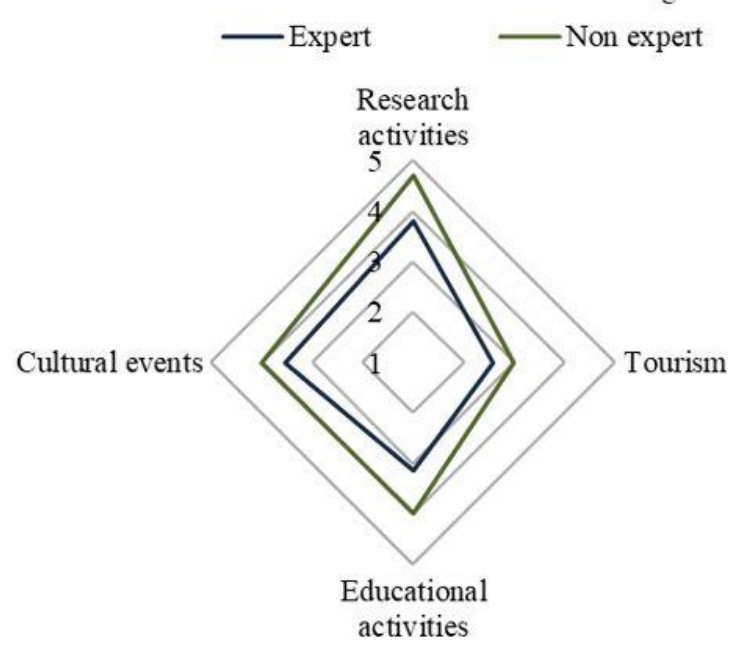

Figure 4. Surface chart. ETI: Compatibility/alternatives uses of the building. Eduardo Torroja Institute

As mentioned in previous sections, tourism is sometimes perceived as an activity detrimental to heritage, so it is not surprising that the results obtained in terms of tourism as a possible alternative activity for the building have a low rating, mainly for the group of experts.

In the case of the Zarzuela Hippodrome, elements such as Events, Dissemination of activities, Library, Miguel Ángel Ribera Library, Eduardo Torroja Museum or Racehorses were valued as a cultural element, among others.

The data collected in this block reflects that $45 \%$ of the respondents report that the dissemination made by the hippodrome is insufficient; assuring that there is hardly any information outside the official website of the hippodrome and that there is no information in the city center of Madrid.

Regarding the consideration of the hippodrome as a potential tourist product, $70 \%$ of respondents confirm that it is. Furthermore, they add, that the hippodrome is ideal as a social meeting place.

Finally, $83 \%$ of respondents say that the most valued element at the hippodrome is the beauty of the surroundings.

To conclude both questionnaires, a final question was included to find out if the users interviewed would recommend visiting both buildings. In the case of the ETI, only the group of external respondents to the building was asked, where $80 \%$ responded that they would recommend the visit.

In the case of the Zarzuela hippodrome, $100 \%$ of the answers were affirmative.

Generally, although the hippodrome, in addition to racing and training, offers a varied leisure offer dedicated to concerts, gastronomy and shopping, it is perceived as a sports and leisure center and not as a cultural resource. In the same way, the ETI, which is mainly considered as a work center, can hardly carry out certain activities (maybe in other periods or in certain facilities of the institute) $100 \%$ linked to tourism.

In both cases, the lack of knowledge of certain respondents seems to be a cause of the lack of appreciation of the buildings as an element of architectural, cultural, aesthetic and historical value. Finally, in both cases, the cultural offer seems not to be sufficient, focusing both buildings on their main activities and leaving in the background a management aimed at attracting tourist interest groups or improving their advertising, as well as accesses and signposting, to bring Torroja's architecture closer to the community.

\section{CONCLUSION}

The $20^{\text {th }}$-century concrete-based cultural heritage is still a great unknown to many people. The perception of the aesthetics of certain modernist buildings is sometimes not appreciated by the non-specialist public. This fact means that many of these buildings often do not constitute part of the tourist experience, unless, there is a significant development in the management and environment of the cultural asset. In order to know how to carry this out, it is necessary to know the existing appreciation of the visitors who come to these apparently undervalued buildings. Based on the analysis carried out in this paper, it has been possible to obtain a preliminary reflection on the level of appreciation and/or awareness of the users interviewed about two modernist buildings of the $20^{\text {th }}$-century by Eduardo Torroja: The Zarzuela hippodrome and the Eduardo Torroja Institute (both located in Madrid, Spain).

The results obtained provide a new perspective on the valuation of both buildings. This information is especially useful for the managers, who will be able to identify and value those "problematic" elements that make it difficult to value the buildings and attract a greater flow of visitors, which is mainly pursued by the administration of the Zarzuela Hippodrome. Regarding the ETI, the managers will also be able to know the existing level of appreciation in order to promote new uses of the facilities and/or improve the diffusion of Eduardo Torroja's legacy.

In this sense, tourism as a means to promote culture to society represents a very useful tool to improve social awareness of this type of cultural assets. Due to the complexity of measuring the social value of such a specific type of cultural asset, it was considered appropriate to establish a model already used in previous studies, including the case study of the Eduardo Torroja Institute as a joint analysis between both buildings of similar architectural characteristics.

On the other hand, this study must be accompanied by a technical analysis of both buildings, which will allow the completion of the study and which, in turn, will form a previous, useful and necessary document for decision-making.

It is necessary to add that the intention of this paper is not to reflect the heritage assessment of the buildings analysed, but to give visibility to those aspects that could be hindering the management of both buildings in relation to the knowledge and awareness of society about the Eduardo Torroja's work. Likewise, it is intended to mark out a path to follow that shows the direction to be taken in order to achieve a greater affluence of visitors and with it a greater profitability or economic viability, without undermining its preservation and always considering ecological and sustainable models for the asset and its environment.

It should be noted that due to the difficulty in interviewing a greater number of people external to the Eduardo Torroja Institute (non-experts), a more in-depth study should be carried out on this building, where a greater number of people can be involved in order to better establish the dividing line between expert and non-expert users of the ETI.

This same approach can be used for other studies related to estate valuation. However, it requires samples that represent the population as faithfully as possible and a high level of participation by the managers and administrations involved. That this paper be considered, thus as an invitation for the development of more in-depth studies linking heritage and tourism as an opportunity for its enhancement. 


\section{ACKNOWLEDGMENT}

InnovaConcrete Project, funding from the European Union's Horizon 2020 research and innovation programme under grant agreement No 760858, supported this work. The administrators of the Zarzuela hippodrome and the staff of Eduardo Torroja Institute, who allowed the data collection, also supported the study.

\section{REFERENCES}

[1] Valença, J., Almeida, C., Júlio, E. (2012). Concrete heritage: Tentative guidelines for the 'patch restoration method'. ICCRRR 2012 - 3rd International Conference on Concrete Repair, Rehabilitation and Retrofitting ICCRRR 2012 - 3rd International Conference on Concrete Repair, Rehabilitation and Retrofitting, pp. 1023-1028.

[2] Camões, A., Ferreira, R.M. (2010). Technological evolution of concrete: From ancient times to ultra highperformance concrete. Structures and Architecture Cruz (Ed.), Taylor \& Francis Group, London, 1571-1578.

[3] Fadrique, L., del Mar, M. (2018). Cubiertas laminares en España. Dos casos en Madrid. http://oa.upm.es/52124/, accessed on Sept. 10, 2019.

[4] Hipódromo de la Zarzuela. https://www.hipodromodelazarzuela.es, accessed on Sep. 2, 2019.

[5] Instituto de Ciencias de la Construcción Eduardo Torroja. https://www.ietcc.csic.es/, accessed on Sept. 10, 2019.

[6] López, G.C. (2019). Reflexión crítica sobre el brutalismo. Rev científica Arquit y Urban, 40(2): 5-20.

[7] Banham, R. (2011). The new brutalism. Spring, 136: 1928. http://dx.doi.org/10.1162/OCTO_a_00034

[8] Sánchez, M.L., Cabrera, A.T., Del Pulgar, M.L.G. (2020). Guidelines from the heritage field for the integration of landscape and heritage planning: A systematic literature review. Landscape and Urban Planning, 204: 103931. https://doi.org/10.1016/j.landurbplan.2020.103931

[9] Prats, L. (2011). La viabilidad turística del patrimonio. Revista de Turismo y Patrimonio Cultural, 9(2): 249-264. http://dx.doi.org/10.25145/j.pasos.2011.09.023

[10] McIntosh, A.J. (1999). Into the tourist's mind: Understanding the value of the heritage experience. Journal of Travel \& Tourism Marketing, 8(1): 41-64. https://doi.org/10.1300/J073v08n01_03

[11] McKercher, B., Ho, P.S.Y. (2006). Assessing the tourism potential of smaller cultural and heritage attractions. Journal of Sustainable Tourism, Routledge, 14(5): 473488. https://doi.org/10.2167/jost620.0

[12] Laing, J., Wheeler, F., Reeves, K., Frost, W. (2014). Assessing the experiential value of heritage assets: A case study of a Chinese heritage precinct, Bendigo, Australia. Tourism Management, 40: 180-192. http://dx.doi.org/10.1016/j.tourman.2013.06.004

[13] Taylor, J.P. (2001). Authenticity and sincerity in tourism. Annals of Tourism Research, Elsevier, 28(1): 7-26.

[14] Aziz, A.A., Zulkifli, M.H. (2019). Users' perception and post-conservation evaluation of kampung Teluk Memali mosque in Ipoh, Perak, Malaysia. International Journal of Heritage Architecture, 2(4): 496-508. http://dx.doi.org/10.2495/HA-V2-N4-496-508

[15] ICOMOS. General Assembly. Charter for the Conservation of Historic Towns and Urban Areas (Washington Charter 1987). www.icomos.org/charters/towns_e.pdf, accessed on Apr. 5, 2019.

[16] Ramírez-Guerrero, G., Arcila-Garrido, M., Chica-Ruiz, A., Benitez-López, D. (2019). Concrete as heritage: Social perception and its valuing. The Zarzuela Hippodrome case. WIT Transactions on The Built Environment, $191(11)$ 17-27. https://doi.org/10.2495/STR190021 